\title{
Avaliação da Atividade Antibacteriana de folhas de Myrtus communis L. (Myrtaceae)
}

\author{
Luiz Estevão Salvagnini, ${ }^{1}$ José Ricardo S. Oliveira, ${ }^{1}$ Luis Eduardo dos Santos, ${ }^{2}$ Raquel \\ Regina D. Moreira, ${ }^{2}$ Rosemeire Cristina L. R. Pietro*,3 \\ ${ }^{1}$ Centro Universitário de Araraquara, UNIARA, Curso de Farmácia, 14801-902 \\ Araraquara-SP, Brasil, \\ ${ }^{2}$ Departamento de Princípios Ativos Naturais e Toxicologia, Faculdade de Ciências Farmacêuticas, UNESP, \\ Rodovia Araraquara-Jaú Km 1, 14801-902 Araraquara-SP, Brasil, \\ ${ }^{3}$ Departamento de Fármacos e Medicamentos, Faculdade de Ciências Farmacêuticas, UNESP, Rodovia \\ Araraquara-Jaú Km 1, 14801-902 Araraquara-SP, Brasil,
}

\begin{abstract}
RESUMO: O óleo essencial e o extrato etanólico obtidos a partir de folhas de Myrtus communis foram avaliados quanto 'a atividade inibitória frente a vários microrganismos. Os halos de inibição de crescimento foram avaliados através das técnicas de "template" e difusão em disco para as linhagens de Staphylococcus aureus, Staphylococcus epidermidis, Escherichia coli, Bacillus subtilis e Serratia marcescens. Os resultados obtidos evidenciaram que o óleo de $M$. communis apresentou atividade antibacteriana superior ao extrato etanólico frente a todas as bactérias. A atividade demonstrada tanto para o óleo como para o extrato etanólico frente a algumas linhagens, foi melhor evidenciada pela técnica "template". E. coli foi resistente ao óleo e extrato etanólico testados.
\end{abstract}

Unitermos: Myrtus communis, atividade antimicrobiana, óleo essencial, extrato etanólico.

\begin{abstract}
Evaluation of the antibacterial activity of Myrtus communis L. (Myrtaceae) leaves". We have studied the crude essential oil and crude ethanol extract from Myrtus communis leaves for possible antimicrobial activity against pathogenic bacteria. The halos of growth inhibition had been evaluated through the techniques of "template" and disk diffusion assays to the strains Staphylococcus aureus, Staphylococcus epidermidis, Escherichia coli, Bacillus subtilis and Serratia marcescens. The results demonstrated that M. communis oil presented superior antibacterial activity to all strains. The template assay was the best method to determine the antibacterial activity exhibited by the oil and extract to the strains. E. coli was resistant to the oil and ethanol extract tested.
\end{abstract}

Keywords: Myrtus communis, antimicrobial activity, essential oil, ethanol extract.

\section{INTRODUÇÃO}

A utilização das plantas medicinais é uma das mais antigas armas empregadas para o tratamento de enfermidades humanas e muito da informação a respeito de seu uso vem através da sabedoria popular (Funke \& Melzig, 2006; Biavatti et al., 2007; Oliveira et al., 2007; Agra et al., 2007). Dados da Organização Mundial de Saúde (WHO, 2002) mostram que cerca de $80 \%$ da população mundial faz uso de algum tipo de planta na busca de alívio de alguma sintomatologia dolorosa ou desagradável (WHO, 2002). A utilização de plantas medicinais, prática tradicional ainda existente entre os povos de todo o mundo, tem recebido incentivos da própria Organização Mundial de Saúde (WHO, 2002). São muitos os fatores que vêm colaborando para o desenvolvimento de práticas de saúde que incluam plantas medicinais, principalmente econômicos e sociais (Elisabetsky, 1991; WHO, 2002; Albuquerque \& Hanazaki, 2006; Silva et al., 2006).

Myrtus communis L. Myrtaceae, conhecida popularmente como "mirta", é uma planta tradicionalmente utilizada no sul do Brasil e no Uruguai. A folha é empregada no tratamento de problemas estomacais, na forma de infusão e apresenta também efeitos antihiperglicêmicos e antimutagênicos (Elfellah et al., 1984; Hayder et al., 2003). Fitohemaglutininas de suas sementes usadas in vitro tiveram efeito antilipêmico útil para auxiliar o diagnóstico clínico de parâmetros bioquímicos em soros lipêmicos (Ortega \& Rodenas, 1979). Triagem fitoquímica preliminar de suas folhas demonstrou a presença de taninos e acilfloroglucinol (El-Sissi \& El-Ansary, 1967; Appendino et al., 2002).

O objetivo deste trabalho foi analisar a atividade de inibição de crescimento de várias cepas de microrganismos patogênicos na presença do óleo 
essencial bruto e extrato etanólico obtidos a partir de folhas de Myrtus communis.

\section{MATERIAL E MÉTODOS}

\section{Material vegetal}

As folhas de $M$. communis foram coletadas de um espécime em Março de 2002, no município de Santana do Livramento, Estado do Rio Grande do Sul, Brasil (coleta 002-JAR, João Aristeu da Rosa). Uma exsicata foi confeccionada e enviada para identificação no Herbário do Instituto de Biociências da UNESP de Rio Claro - SP. As folhas foram secas em estufa com circulação forçada de ar a $40{ }^{\circ} \mathrm{C}$. Em seguida foram pulverizadas em moinho de facas, para facilitar a extração de seus constituintes químicos.

\section{Preparação de extratos e óleo essencial}

Os extratos foram preparados por turboextração durante 15 minutos a $40{ }^{\circ} \mathrm{C}$, com etanol:água (7:3) e concentrados sob pressão reduzida em evaporador rotatório $\left(40{ }^{\circ} \mathrm{C}\right)$. A seguir, o extrato foi dissolvido em dimetilsulfóxido para a concentração de $100 \mathrm{mg} / \mathrm{mL}$. O óleo essencial foi obtido por extração de arraste a vapor no aparelho de Clevenger modificado (Wasicky, 1963).

\section{Microrganismos e meios}

As linhagens bacterianas usadas neste estudo foram Staphylococcus aureus (ATCC 25923), Staphylococcus epidermidis (ATCC 27853), Escherichia coli (ATCC 25922), Bacillus subtilis (ATCC 6633) e Serratia marcescens (cepa de campo). As linhagens foram mantidas para crescimento em meio MüellerHinton por 24 horas a $37{ }^{\circ} \mathrm{C}$ sendo transferidas para meios líquidos BHI (Infuso cérebro coração - Brain Heart Infusion) para testes de atividade antimicrobiana.

\section{Ensaios de atividade antimicrobiana}

Uma colônia de cada cepa crescida previamente em meio Müeller-Hinton por 24 horas a $37{ }^{\circ} \mathrm{C}$ foi

Tabela 1. Atividade antimicrobiana do óleo essencial e extrato etanólico de Myrtus communis.

\begin{tabular}{lcccccc}
\hline \multirow{2}{*}{ Amostras } & \multicolumn{4}{c}{ "Template" } \\
\cline { 2 - 7 } & Óleo & Extrato & Ampicilina & Óleo & Difusão em disco \\
\hline S. aureus & 20 & 15 & 21 & 15 & 12 & Ampicilina \\
S. epidermidis & 20 & 12 & 26 & 15 & $-{ }^{\mathrm{b}}$ & 22 \\
E. coli & - & - & 20 & - & - & 21 \\
B. subtilis & 17 & 15 & 26 & 15 & - & 26 \\
S. marcescens & 10 & - & 15 & 13 & 11 & 15 \\
\hline
\end{tabular}

(a) Os halos estão expressos em mm.

(b) -: significa ausência de halo.

transferida para caldo BHI (Brain Heart Infusion) e incubada a $37^{\circ} \mathrm{C}$ por 24 horas para atingir o crescimento exponencial. A partir deste inóculo foi ajustada turvação até a escala 0,5 de Mc Farland (1-3 x $10^{8} \mathrm{UFC} / \mathrm{mL}$, unidades formadoras de colônia) e em seguida as bactérias foram diluídas 1:100 para uso no ensaio de atividade antimicrobiana (Bauer et al., 1966).

A atividade inibitória foi verificada pelas técnicas "template" e difusão em disco. As suspensões de bactérias convenientemente diluídas foram adicionadas às placas contendo meio de Müeller-Hinton fundido. Após solidificação dos meios, os discos de papel ou os poços receberam $20 \mu \mathrm{L}$ do óleo essencial ou dos extratos $(100 \mathrm{mg} / \mathrm{mL})$ os quais foram aplicados às placas, que a seguir foram incubadas a $37^{\circ} \mathrm{C}$ durante 24 horas. Após o período de incubação foi realizada leitura visual observando-se o halo de inibição de crescimento bacteriano quantificado $\mathrm{em} \mathrm{mm}$ com o auxílio de paquímetro. Paralelamente foram realizados controles dos crescimentos bacterianos, dos solventes utilizados e ampicilina $(10 \mu \mathrm{g} / \mathrm{mL})$ como controle positivo (Balows et al., 1991). Todos os ensaios foram realizados em triplicatas.

\section{RESULTADOS E DISCUSSÃO}

Espécies vegetais continuam a representar fontes de inúmeras drogas e estudos relacionados à investigação de propriedades terapêuticas exibidas por estas constituem-se em importante ferramenta para esclarecimento científico. Assim uma espécie pode ser analisada quanto aos seus constituintes químicos obtidos em diferentes situações. Os óleos essenciais são misturas constituídas por um número variado de substâncias orgânicas com estruturas relativamente simples, onde os principais componentes provêm de rotas secundárias do metabolismo de plantas, como os monoterpenos, sesquiterpenos e fenilpropanóides. Essas composições naturais se tornaram um conveniente atrativo devido às suas propriedades biológicas e organolépticas. Entre as espécies reconhecidas como produtoras de óleo essencial anti-séptico destacam-se o Ocimum gratissimum L., conhecido popularmente como alfavacão (Ntezurubanza et al., 1987), o Cymbopogon citratus (DC) Stapf ou capim-limão (Onawunmi \& Ogunlana, 1986) e Salvia 
officinalis L., a sálvia. O óleo essencial de Cymbopogom citratus (DC) Stapf. é constituído de mirceno, neral, geranial e outros compostos não identificados (Craveiro, 1981) sendo utilizado contra gripes, disenteria, dores de cabeça e também como calmante e antiespasmódico; além disso, possui atividade antimicrobiana e antihipertensiva (Onawunmi \& Ogunlana, 1986; Singi et al., 2005). Podemos observar na Tabela 1 que o óleo essencial, avaliado pela técnica "template", apresentou atividade antimicrobiana frente a todas as linhagens testadas, exceto $E$. coli, enquanto o extrato de $M$. communis, na concentração utilizada, não foi capaz de inibir o crescimento para $E$. coli $\mathrm{e} S$. marcescens. O efeito antibacteriano obtido pelo óleo essencial comparado ao extrato frente a $S$. aureus foi 1,3 vezes superior, enquanto que para $S$. epidermidis foi 1,7 vezes e $B$. subtilis 1,1 vezes superior através da técnica "template".

De acordo com os resultados obtidos pelo ensaio de difusão em disco o extrato de M. communis, mostrou que $E$. coli e $B$. subtilis apresentaram resistência, sendo que frente a $E$. coli o óleo também não mostrou atividade inibitória. O efeito antibacteriano obtido pela técnica de difusão em disco observado para o óleo em relação ao extrato frente a $S$. aureus foi 1,3 vezes superior enquanto para $B$. subtilis foi 1,4 vezes.

Podemos notar para o óleo essencial e extrato etanólico de M. communis que os níveis de inibição de crescimento bacteriano pela técnica de difusão em disco foram menores em relação aos controles de ampicilina exibidos na Tabela 1. Entretanto, os dados indicam que a atividade antibacteriana para o óleo essencial e extrato hidroalcoólico de $M$. communis frente a algumas linhagens, foi melhor evidenciada pela técnica "template". Estes resultados são concordantes com a literatura que mostra estudos comparando atividade antimicrobiana de algumas espécies vegetais, entre as quais Achillea millefolium subsp. millefolium, Achillea biebersteini, Satureja hortensis e Thymus pectinatus nos quais os óleos apresentam maior atividade inibitória sobre os microrganismos (Candan et al., 2003; Sokmen et al., 2004; Gulluce et al., 2003; Vardar-Unlu et al., 2003). Neste trabalho demonstrou-se que entre as bactérias gram negativas, a $E$. coli exibiu maior resistência aos efeitos inibitórios de $M$. communis pela técnica "template" e difusão em disco.

Os resultados evidenciaram que o óleo de $M$. communis apresentou atividade antibacteriana com inibição de $63,5 \%$ para $B$. subtilis a $95,2 \%$ frente a $S$. aureus pela técnica "template". Podemos notar que pela técnica de difusão em disco, os valores de inibição do crescimento bacteriano foram $57,7 \%$ a $71,4 \%$. A ação antibacteriana obtida pelo extrato apresentou índices de inibição de crescimento menores, quando comparado ao controle. Podem ser citadas as propriedades antibacterianas frente a $S$. aureus e $S$. epidermidis dos óleos da espécie Marlierea eugeniopsoides (Limberger et al., 1998), de Melaleuca alternifolia frente a várias espécies de lactobacilos (Hammer et al., 1999) e óleos essenciais de Psidium que foram ativos contra S. aureus e Pseudomonas aeruginosa (Santos et al., 1997). A comparação de dados obtidos com óleos e extratos deve ser analisada levando-se em consideração que a composição dos mesmos varia em função das condições climáticas e ambientais (Janssen et al., 1987; Sivropoulou et al., 1995; Tavares et al., 2005; Franco et al., 2005; Potzernheim et al., 2006; Carvalho-Filho et al., 2006). Além disto, o método a ser utilizado para determinar a atividade antimicrobiana e a seleção de linhagens pode influenciar o resultado obtido (Janssen et al., 1987; Nascimento et al., 2007), sendo o método de difusão em disco uma técnica bastante recomendada para avaliação de óleos (Morris et al., 1979; SmithPalmer et al.,1998).

Atualmente observa-se uma forte tendência pelo uso de plantas aromáticas para muitos propósitos, incluindo seu uso como agentes antimicrobianos, considerando-se a composição e o potencial antimicrobiano de seus respectivos óleos essenciais. Ao lado das atividades reportadas para M. communis, da presença de taninos e acilfloroglucinol (El-Sissi \& El-Ansary, 1967; Appendino et al., 2002) nas folhas, a atividade antibacteriana de seu óleo essencial e extrato etanólico aquidemonstradas merecemmaior investigação para possível identificação dos compostos responsáveis pela ação antimicrobiana de M. communis.

\section{AGRADECIMENTOS}

Os autores agradecem ao Sr. João Medeiros da Secretaria de Saúde do Estado do Rio Grande do Sul pelo auxílio na coleta da espécie e ao Prof. Dr. João Aristeu Rosa pela cessão do material para o trabalho. Também expressamos nossa gratidão ao Prof. Dr. Luis Vitor Silva do Sacramento pelo auxílio na execução da exsicata.

\section{REFERÊNCIAS}

Agra MF, França PF, Barbosa-Filho JM 2007. Synopsis of the plants known as medicinal and poisonous in Northeast of Brazil. Rev Bras Farmacogn 17: 114-140.

Albuquerque UP, Hanazaki N 2006. As pesquisas etnodirigidas na descoberta de novos fármacos de interesse médico e farmacêutico: fragilidades e pespectivas. Rev Bras Farmacogn 16(Supl.): 678-689.

Appendino G, Bianchi F, Minassi A, Sterner O, Ballero M, Gibbons S 2002. Oligomeric acylphloroglucinols from myrtle (Myrtus communis). J Nat Prod 65: 334-338.

Balows A, Hausler WJ, Hermann KL, Isenberg HD, Shadamyit J 1991. Manual of Clinical Microbiology. $5^{\text {th }}$ ed. Washington (DC): American Society for Microbiology.

Bauer AW, Kirby MDK, Sherries JC, Truck, M 1966. Antibiotic susceptibility testing by a standardized single disk method. Am J Clin Pathol 45: 493-496. 
Biavatti MW, Marensi V, Leite SN, Reis A 2007. Ethnopharmacognostic survey on botanical compendia for potential cosmeceutic species from Atlantic Forest. Rev Bras Farmacogn 17: 640-653.

Candan F, Unlu M, Tepe B, Daferra D, Polissiou M, Sokmen A, Akpulat HA 2003. Antioxidant and antimicrobial activity of the essential oil and methanol extracts of Achillea millefolium subsp. millefolium Afan. (Asteraceae). J Ethnopharmacol 87: 215-220.

Carvalho-Filho JLS, Blank AF, Alves PB, Ehlert PAD, Melo AS, Cavalcanti $\mathrm{SCH}$, Arrigoni-Blank MF, SilvaMann R 2006. Influence of the harvesting time, temperature and drying period on basil (Ocimum basilicum L.) essential oil. Rev Bras Farmacogn 16: 24-30.

Craveiro AA, Fernandes AG, Andrade CHS, Matos FJA, Alencar JW, Machado MIL 1981. Óleos Essenciais de Plantas do Nordeste. Fortaleza: Edição UFC, p. 210.

El-Sissi HI, El-Ansary MA. 1967. Tannins and polyphenolics of the leaves of Myrtus communis. Planta Med 15: 41-51.

Elfellah MS, Akhter MH, Khan MT 1984. Antihyperglycaemic effect of an extract of Myrtus communis in streptozotocin-induced diabetes in mice. J Ethnopharmacol 11: 275-281.

Elisabetsky E 1991. Sociopolitical, economical and ethical issues in medicinal plant research. J Ethnopharmacol 32: 235-239.

Franco J, Nakashima T, Franco L, Boller C 2005. Composição química e atividade antimicrobiana in vitro do óleo essencial de Eucalyptus cinerea F. Mull. ex Benth., Myrtaceae, extraído em diferentes intervalos de tempo. Rev Bras Farmacogn 15: 191-194.

Funke I, Melzig MF 2006. Traditionally used plants in diabetes therapy - phytotherapeutics as inhibitors of $\alpha$-amylase activity. Rev Bras Farmacogn 16: 1-5.

Gulluce M, Sokmen M, Daferera D, Agar G, Ozkan H, Kartal N, Polissiou M, Sokemen A, Sahin F 2003. In vitro antibacterial, antifungal, and antioxidant activities of the essential oil and methanol extracts of herbal parts and callus cultures of Satureja hortensis L. J Agric Food Chem 51: 3958-3965.

Hammer KA, Carson CF, Riley TV 1999. In vitro susceptibilities of lactobacilli and organisms associated with bacterial vaginosis to Melaleuca alternifolia (Tea Tree) oil Antimicrob Agents Chemother 43: 196.

Hayder N, Kilani S, Abdelwahed A, Mahmoud A, Meftahi K, Ben Chibani J, Ghedira K, Chekir-Ghedira L 2003. Antimutagenic activity of aqueous extracts and essential oil isolated from Myrtus communis. Pharmazie 58: 523-534.

Janssen AM, Scheffer JJC, Baerheim Svendsen A. 1987. Antimicrobial activity of essential oils: a 1976-1986 literature review. Aspects of the test methods. Planta Med 53: 395-398.

Limberger RP, Apel MA, Sobral M, Schapoval ES, Henriques AT 1998. Investigação da atividade antimicrobiana do óleo volátil de espécies da família Myrtaceae. Rev Bras Farm 79: 49-52.

Morris JA, Khettry A, Seitz EW 1979. Antimicrobial activity of aroma chemicals and essential oils. J Am Oil Chem Soc 56: 595-603.

Nascimento PFC, Nascimento AC, Rodrigues CS, Antoniolli AR, Santos PO, Barbosa Júnior, Trindade RC 2007.
Atividade antimicrobiana dos óleos essenciais: uma abordagem multifatorial dos métodos. Rev Bras Farmacogn 17: 108-113.

NtezurubanzaL, Scheffer JJC, SwendsenAB 1987. Composition of the essential oil of Ocimum gratissimum grown in Rwanda. Planta Med 53: 421-423.

Oliveira FQ, Gobira B, Guimarães C, Batista J, Barreto M, Souza M 2007. Espécies vegetais indicadas na odontologia. Rev Bras Farmacogn 17: 466-476.

Onawunmi GO, Ogunlana EO 1986. A study of the antibacterial activity of the essential oil of lemon grass (Cymbopogon citratus). Int J Crude Drug Res 24: 64-68.

Ortega M, Rodenas S. 1979. Myrtus communis L. phytohemagglutinins as a clarifying agent for lipemic sera. Clin Chim Acta 92: 135-139.

Potzernheim MCL, Bizzo HR, Vieira RF 2006. Análise dos óleos essenciais de três espécies de Piper coletadas na região do Distrito Federal (Cerrado) e comparação com óleos de plantas procedentes da região de Paraty, RJ (Mata Atlântica). Rev Bras Farmacogn 16: 246-251.

Santos FA, Rao VS, Silveira ER 1997. The leaf essential oil of Psidium guyanensis offers protection against pentylenetetrazole-induced seizures. Planta Med 63: 133-135.

Silva MIG, Gondim APS, Nunes IFS, Sousa FCF 2006. Utilização de fitoterápicos nas unidades básicas de atenção à saúde da família no município de Maracanaú (CE). Rev Bras Farmacogn 16: 455-462.

Singi G, Damasceno DD, D’Andréa ED, Silva GA 2005. Efeitos agudos dos extratos hidroalcoólicos do alho (Allium sativum L.) e do capim-limão (Cymbopogon citratus (DC) Stapf) sobre a pressão arterial média de ratos anestesiados. Rev Bras Farmacogn 15: 94-97.

Sivropoulou A, Kokkini S, Lanaras T, Arsenakis M 1995. Antimicrobial activity of mint essential oils. J Agric Food Chem 43: 2384-2388.

Smith-Palmer A, Stewart J, Fyfe L 1998. Antimicrobial properties of plant essential oils and essences against five important food-borne pathogens. Lett Appl Microbiol 26: 118-122.

Sokmen A, Sokmen M, Daferra D, Polissiou M, Candan F, Unlu M, Akpulat HA 2004. The in vitro antioxidant and antimicrobial activities of the essential oil and methanol extracts of Achillea biebersteini Afan. (Asteraceae). Phytother Res 18: 451-456.

Tavares E.S, Julião LS, Lopes D, Bizzo HR, Lage CLS, Leitão SG 2005. Análise do óleo essencial de folhas de três quimiotipos de Lippia alba (Mill.) N.E.Br. (Verbenaceae) cultivados em condições semelhantes. Rev Bras Farmacogn 15: 1-5.

Vardar-Unlu G, Candan F, Sokemen A, Daferera D, Polisssiou M, Sokmen M, Donmez E, Tepe B 2003. Antimicrobial and antioxidant activity of the essential oil and methanol extracts of Thymus pectinatus Fisch. et Mey. var. pectinatus (Lamiaceae). J Agric Food Chem 5: 63-67.

Wasicky R 1963. Uma modificação do aparelho de Clevenger para extração de óleos essenciais. Rev Fac Farm Bioquim 1: 7-81.

WHO 2002. Report on infectious diseases. World Health Organization, Geneva, Switzerland. 